\title{
Advantages of foam flow usage for heat transfer process
}

\author{
J. Gylys ${ }^{1}$, S. Sinkunas ${ }^{2}$, S. Ziedelis ${ }^{2} \&$ T. Zdankus ${ }^{1}$ \\ ${ }^{1}$ Energy Technology Institute, \\ Kaunas University of Technology, Lithuania \\ ${ }^{2}$ Department of Thermal and Nuclear Energy, \\ Kaunas University of Technology, Lithuania
}

\begin{abstract}
Size and mass reduction in heat exchangers are important but challenging issues. It can be achieved by enhancing the heat transfer rates within the exchanger and applying a two-phase system as a coolant, which provides significant benefits. Two-phase systems, such as a foam flow, have a number of advantages in comparison with single-phase systems. For example, they require smaller coolant flow rates, and lower energy consumption in delivering the coolant to the region where heat transfer process is to take place. They also provide larger variations of heat transfer intensity depending on foam hydrodynamics and its chemical characteristics. Two-phase foam flow has a number of specific peculiarities, which do not allow the application of the established analytic methods in estimating the heat transfer characteristics. Experimental methods were therefore adopted and the heat transfer of in-line and staggered tube bundles were investigated in a vertical channel (with 180 degree turn) with foam flowing both upwards and downwards. The dependence of tube bundle heat transfer on the foam flow velocity, direction and volumetric void fraction was analyzed. Results of the investigation were generalized by criterion equations, which can be used for the design of the heat exchangers, utilizing statically stable foam.

Keywords: heat exchanger, experimental set-up, foam flow, heat transfer, tube bundle.
\end{abstract}

\section{Introduction}

Foam is distinguished by an especially large inter-phase contact surface and can be used as a coolant in heat exchangers or foam apparatus. One significant 
requirement has to be fulfilled in this case - foam must keep in its initial structure and bubbles dimensions for long intervals of time. The characteristics of one type of foam, namely statically stable foam, have been demonstrated to be ideal for this application [1]. Statically stable foam can be generated from the solutions which have less then pure liquid surface tension [1,2]. Even small concentrations of detergents may be the reason of intensive generation of statically stable foam due to the bubbling of gas. The detergent's concentration must ensure the required stability of the foam and must satisfy defined volumetric void fraction requirements [1].

Heat transfer of different heated surfaces and tube bundles was excessively investigated for single-phase fluids [3, 4]. However, past investigations of heat transfer of the tube bundles in the foam flow are limited. In our previous work on a single tube [1], the heat transfer to upward statically stable foam flow was studied. The heat transfer from a bundle of tubes was also investigated, where tubes were arranged in a staggered $[5,6]$ and in-line [7, 8] arrangements with foam flowing upwards and downwards. It was noticed that the heat transfer coefficient from a single tube to statically stable foam flow varied from 350 to $682 \mathrm{~W} /\left(\mathrm{m}^{2} \mathrm{~K}\right)$ and influenced by foam volumetric void fraction variations [1]. This data are relevant for an external diameter equal to $0.014 \mathrm{~m}$ and flow velocity of $0.4 \mathrm{~m} / \mathrm{s}$. In comparison with single-phase fluid flow, the value of the heat transfer coefficient for a single tube was equal to $16 \mathrm{~W} /\left(\mathrm{m}^{2} \mathrm{~K}\right)$ (for air flow) and $3963 \mathrm{~W} /\left(\mathrm{m}^{2} \mathrm{~K}\right.$ ) (for water flow) under the same flow velocity [4]. Density of the same coolants was equal: $1.2 \mathrm{~kg} / \mathrm{m}^{3}$ for air [9], $3.2 \div 5.2 \mathrm{~kg} / \mathrm{m}^{3}$ for foam [1] and $998.2 \mathrm{~kg} / \mathrm{m}^{3}$ for water $(T=293.15 \mathrm{~K}, P=101325 \mathrm{~Pa})[9]$.

Results of the heat transfer analysis for staggered and in-line tube bundles are evaluated in the following sections when laminar statically stable foam flows upwards and downwards.

\section{Experimental set-up}

An experimental set-up consisted of the following main parts: experimental channel, tube bundle, gas and liquid control valves, gas and liquid flow meters, liquid storage reservoir, liquid level control reservoir, air fan, electric current transformer and stabilizer (Fig. 1). Cross section of the experimental channel had dimensions $0.14 \times 0.14 \mathrm{~m}^{2}$; height of it was $1.8 \mathrm{~m}$. Radius of the channel turning was equal to $0.17 \mathrm{~m}$.

Foam flow was generated from the water solution of detergents. Concentration of detergents was kept constant and was equal to $0.5 \%$. Foam flow was produced during gas and liquid contact on the riddle, which was installed at the bottom of the experimental channel. Liquid was delivered from the reservoir to the riddle from the upper side; gas was supplied to the riddle from below.

A schematic view of the experimental channel with the tube bundle is shown in Figure 2. Staggered bundle of tubes consisted of three vertical rows with five tubes in each (Figure 2a)). Spacing between the centres of the tubes across the channel was $s_{1}=0.035 \mathrm{~m}$; spacing along the channel was $s_{2}=0.0175 \mathrm{~m}$. The in- 
line bundle of tubes consisted of five vertical rows with six tubes in each (Figure 2b)). Spacing between the centres of the tubes was $s_{1}=s_{2}=0.03 \mathrm{~m}$. The external diameter of all the tubes was equal to $0.02 \mathrm{~m}$. An electrically heated tube - calorimeter was made from copper and also had an external diameter equal to $0.02 \mathrm{~m}$. Endings of the calorimeter were sealed and insulated. During the experiments calorimeter was placed instead of one tube of the bundle. An electric current value was measured by an ammeter and voltage by a voltmeter. Temperature of the foam flow was measured by two calibrated thermocouples: one in front of the bundle and one behind it. Temperature of the calorimeter surface was measured by eight calibrated thermocouples: six of them were placed around the central part of the tube and two of them were placed in both sides of the tube at a distance of $50 \mathrm{~mm}$ from the central part.

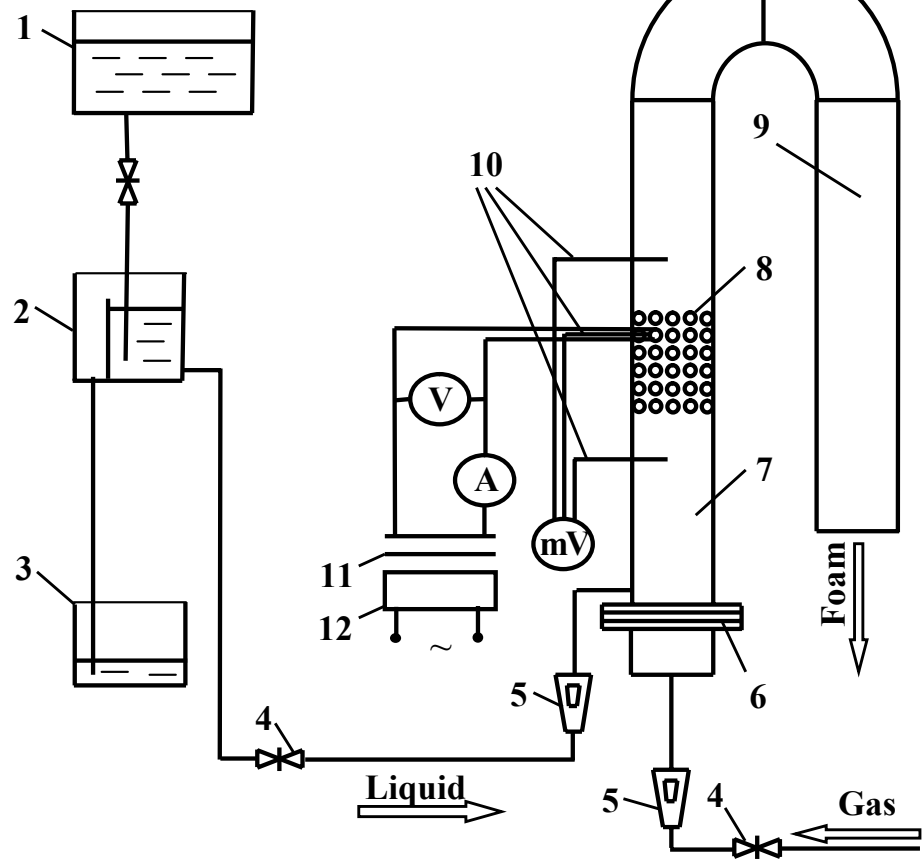

Figure 1: Experimental set-up scheme: 1-liquid reservoir; 2-liquid level control reservoir; 3-liquid receiver; 4-gas and liquid control valves; 5-flow meter; 6-foam generation riddle; 7-experimental channel; 8-tube bundle; 9-output channel; 10-thermocouples; 11-transformer; 12-stabiliser.

Measurement accuracies for flows, temperatures and heat fluxes were of range correspondingly $1.5 \%, 0.15 \div 0.20 \%$ and $0.6 \div 6.0 \%$. 
a)

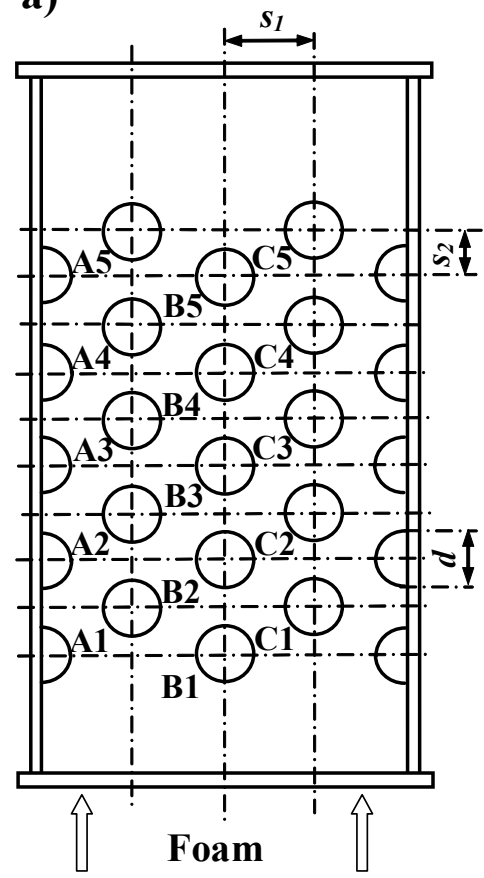

b)

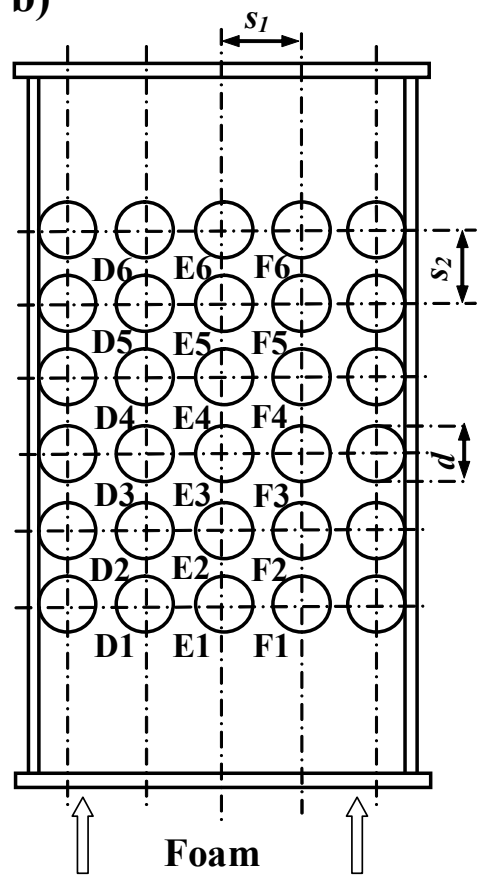

Figure 2: $\quad$ Staggered tube bundle (a) and in-line tube bundle (b) in the upward foam flow.

During the experimental investigation a relationship was obtained between an average heat transfer coefficient $h$ from one side and foam flow volumetric void fraction $\beta$ and gas flow Reynolds number $R_{g}$ from the other side:

$$
N u_{f}=f\left(\beta, \operatorname{Re}_{g}\right) .
$$

Nusselt number was computed by formula

$$
N u_{f}=\frac{h d}{\lambda_{f}} .
$$

where $\lambda_{f}$ is the thermal conductivity of the statically stable foam flow, $\mathrm{W} /(\mathrm{m} \cdot \mathrm{K})$, computed from the equation

$$
\lambda_{f}=\beta \lambda_{g}+(1-\beta) \lambda_{l} .
$$

An average heat transfer coefficient was calculated as

$$
h=\frac{q_{w}}{\overline{\Delta T}} .
$$


Gas Reynolds number of foam flow was computed by formula

$$
\operatorname{Re}_{g}=\frac{G_{g} d}{A v_{g}} .
$$

Foam flow volumetric void fraction can be expressed by the equation

$$
\beta=\frac{G_{g}}{G_{g}+G_{l}} .
$$

The temperatures of the heated tube surface and the foam flow, electric current and voltage were measured and recorded during the experiments. Investigation showed that hydraulic and thermal regime stabilizes completely within 5 minutes after the change of experiment conditions. Therefore measurements were started not earlier than 5 minutes after adjustment of the foam flow parameters. Heat flux density on the tube surface $q_{w}$ was calculated after registration of electric current and voltage. Temperature difference $\overline{\Delta T}$ (between the mean temperatures of the foam flow $\bar{T}_{f}$ and tube surface $\bar{T}_{w}$ ) was calculated after record of heated tube surface and foam flow temperatures.

It is known [1] that there are four main regimes of the statically stable foam flow in the vertical channel of rectangular cross section:

- Laminar flow regime $R e_{g}=0 \div 600$;

- Transition flow regime $R e_{g}=600 \div 1500$;

- Turbulent flow regime $R e_{g}=1500 \div 1900$;

- Emulsion flow regime $R e_{g}>1900$.

Experiments were performed within Reynolds number diapason for gas $\left(R e_{g}\right)$ : $190 \div 440$ (laminar flow regime) and foam volumetric void fraction $(\beta)$ : $0.996 \div 0.998$. Gas velocity for foam flow was changed from 0.14 to $0.32 \mathrm{~m} / \mathrm{s}$.

\section{Results}

An experimental investigation of the staggered tube bundle was performed, where heat transfer from the bundle to the upward statically stable foam flow was studied. This was followed by experiments with downward foam flow. Next, in-line arrangement of tube bundle was considered for upward and downward foam flow.

In order to analyze and compare the experimental results of different type tube bundles, the average heat transfer rate was calculated for the studied cases. The average heat transfer intensity of the tubes of the staggered bundle in upward and downward foam flow is shown in Fig. 3.

The influence of foam flow gas $R e_{g}$ numbers and volumetric void fraction on heat transfer intensity is evaluated for staggered arrangement of tube bundle. The heat transfer rate increased at least 2 times for upward foam flow, when gas flow Reynolds numbers $R e_{g}$ are changed from 190 to 440. It is also intensified with increasing volumetric void fraction. In this case, the heat transfer increased by 2.3 times for $\beta=0.996,2.7$ times for $\beta=0.997$, and by 2.6 times for $\beta=0.998$ (upward foam flow). For downward flow, the heat transfer increased by 2.1 times for $\beta=0.996,1.9$ times for $\beta=0.997$, and by 1.6 times for $\beta=0.998$. 
In case of staggered tube bundle, the average heat transfer in upward foam flow is higher than that in downward foam flow. This statement is valid for entire range of $R e_{g}$ numbers considered in this study, i.e., from 190 to 440 and for volumetric void fraction of $\beta=0.996$. When volumetric void fraction has the values of $\beta=0.997$ and $\beta=0.998$, the heat transfer rate is higher in upward flow only in the interval of $R e_{g}$ from 280 to 440 and interval of $R e_{g}$ from 260 to 440 , respectively.

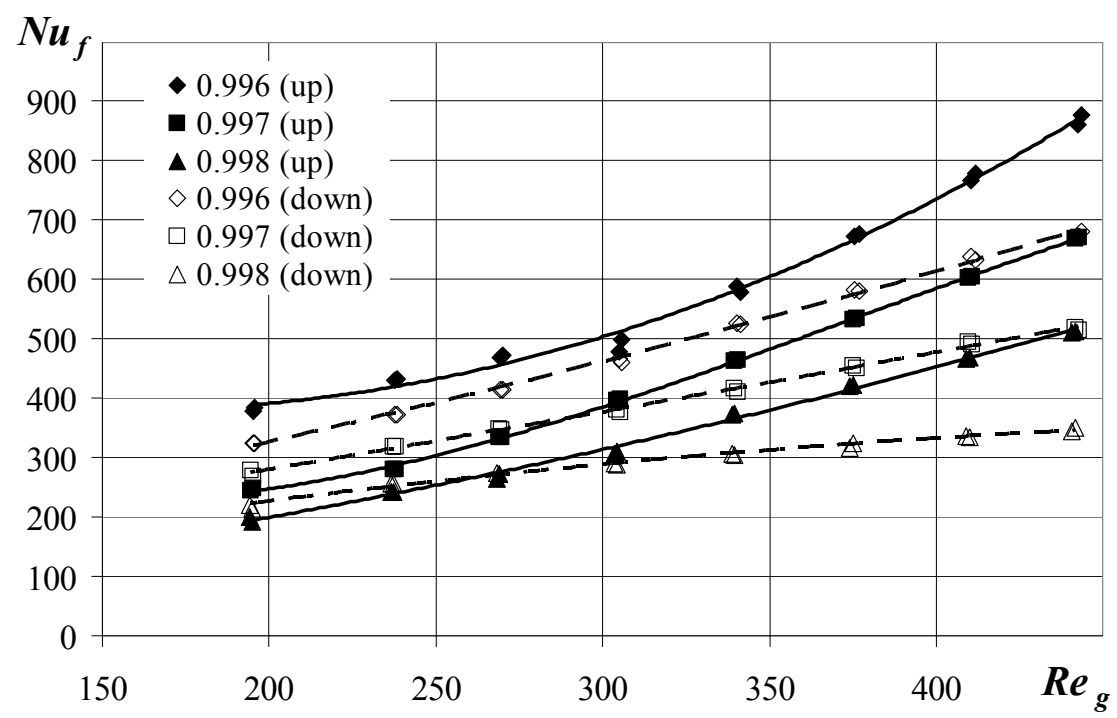

Figure 3: Average heat transfer of the tubes of the staggered tube bundle to the upward and downward foam flow: $\beta=0.996,0.997$ and 0.998 .

The average heat transfer intensity of the in-line bundle for upward and downward foam flow is shown in Fig. 4

The influence of gas flow $R e_{g}$ numbers and volumetric void fraction on heat transfer intensity was also studied for the in-line arrangement of the tube bundle. When the foam flow gas Reynolds number $R e_{g}$ is changed from 190 to 440, the heat transfer rate of the in-line bundle increased by 2.5 times for $\beta=0.996,2.3$ times for $\beta=0.997$, and twice for $\beta=0.998$ in upward foam flow. For downward foam flow, the heat transfer was seen to increase by 2.1 times for $\beta=0.996$, twice for $\beta=0.997$, and by 1.7 times for $\beta=0.998$. The average heat transfer intensity of the tubes of the in-line bundle is higher in downward foam flow for entire range of $R_{g}$ numbers considered in this study, when $\beta=0.996$ and 0.997. For $\beta=0.998$, the heat transfer intensity is slightly higher in upward foam flow only when $R e_{g}$ is more than 410 .

An average heat transfer of staggered tube bundle with upward foam flow is slightly higher than that of the in-line tube bundle for entire interval of $R e_{g}$ numbers. This statement corresponds to volumetric void fraction of $\beta=0.996$. 
When volumetric void fraction is $\beta=0.997$ and 0.998 , the heat transfer is higher only in the interval of $R e_{g}$ from 300 to 440 . The difference between the heat transfer intensity of the staggered and in-line tube bundles varies from $0.5 \%$ to $15 \%$.

In downward foam flow, the heat transfer of the in-line arrangement of the tube bundle was higher than that of the staggered arrangement for the whole interval of $\operatorname{Re}_{g}\left(\operatorname{Re}_{g}=190 \div 440\right)$. This phenomenon can be explained by the fact that the spacing between the horizontal rows of the tubes $\left(s_{2}\right)$ of the staggered tube bundle is 1.7 times less than that of the in-line tube bundle and therefore the influence of "shadow" effect is more significant for the staggered tube bundle. In comparison with the staggered tube bundle, an average heat transfer intensity of the tubes of the in-line tube bundle was higher on average by $39 \%$ for $\beta=0.996$, by $34 \%$ for $\beta=0.997$ and by $23 \%$ for $\beta=0.998$ in downward foam flow.

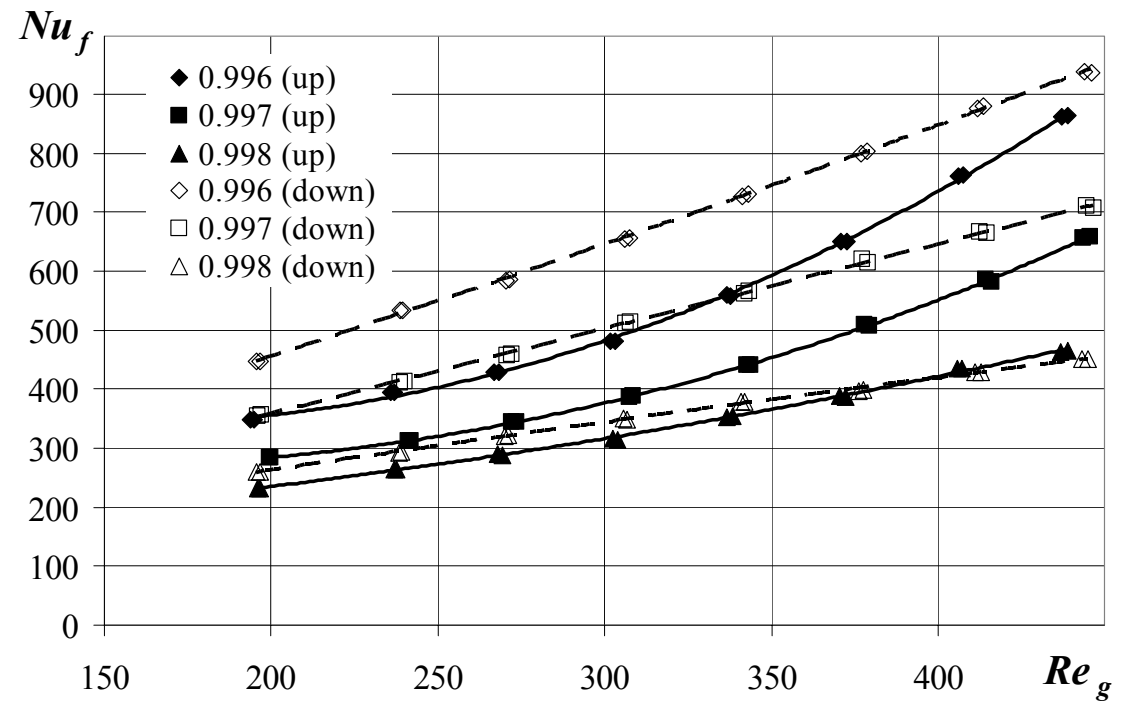

Figure 4: Average heat transfer of the tube of the in-line tube bundle to the upward and downward foam flow: $\beta=0.996,0.997$ and 0.998 .

Experimental results of the heat transfer in both arrangements of tube bundles (staggered and in-line) were generalised by an empirical equation. This equation is based on dependence between Nusselt number $N u_{f}$ and foam flow gas Reynolds number $R e_{g}$, and is suited for both upward and downward flow directions. It is valid for $190<R e_{g}<440$ and for the volumetric void fraction $\beta=0.996,0.997$, and 0.998 , and can be expressed as follows:

$$
N u_{f}=c \beta^{n} \operatorname{Re}_{g}^{m} .
$$

The coefficients $c, n$ and $m$ depend on flow direction, type of tube bundle arrangement as well as $R e$ numbers and volumetric void fraction. For a staggered 
tube bundle with upward foam flow, the coefficients have the following values: $c=1820(\beta-0.99), n=0, m=60.43-60 \beta$ (for the $190<R e_{g}<300$ ) and $c=2.3, n=950$, $m=200.8-200 \beta$ (for the $300<R e_{g}<440$ ). While for a staggered tube bundle with downward foam flow, the coefficients are: $c=64.6, n=844, m=192.02-191.85 \beta$. For in-line tube bundle, the coefficients have following values: i) upward foam flow $c=5.9, n=479, m=125.93-125.3 \beta$ and ii) downward foam flow: $c=12.7$, $n=334, m=115.06-114.6 \beta$.

\section{Conclusions}

An experimental investigation of the heat transfer intensity was performed for the staggered and in-line tube bundles with both upward and downward vertical laminar flow using statically stable foam.

The experimental results showed that the average heat transfer intensity of the staggered and in-line tube bundles (with upward foam flow) varies slightly with a maximum difference of $15 \%$.

The influence of the "shadow" effect is significant for a staggered tube bundle in downward foam flow. Therefore average heat transfer intensity for an in-line tube bundle (downward foam flow) is higher than that for a staggered tube bundle.

The experimental results were generalised by empirical equation, which can be used for the calculation and design of the statically stable foam heat exchangers.

\section{Nomenclature}

$A$ - cross section area of experimental channel, $\mathrm{m}^{2} ; c, m, n$ - coefficients; $d-$ outside diameter of tube, m; $G$ - volumetric flow rate, $\mathrm{m}^{3} / \mathrm{s} ; N u$ - Nusselt number; $q$ - heat flux density, $\mathrm{W} / \mathrm{m}^{2} ; R e$ - Reynolds number; $\bar{T}-$ average temperature, $\mathrm{K} ; h$ - average coefficient of heat transfer, $\mathrm{W} /\left(\mathrm{m}^{2} \cdot \mathrm{K}\right) ; \beta-$ volumetric void fraction; $\lambda$ - thermal conductivity, $\mathrm{W} /(\mathrm{m} \cdot \mathrm{K}) ; v-$ kinematic viscosity, $\mathrm{m}^{2} / \mathrm{s}$.

\section{Indexes}

$f$-foam;

$g$ - gas;

$l$ - liquid;

$w$ - wall of heated tube.

\section{References}

[1] Gylys, J., Hydrodynamics and Heat Transfer Under the Cellular Foam Systems, Technologija: Kaunas, 1998.

[2] Sadoc, J. F., Rivier, N., Foams and Emulsions, Nato ASI Series, 1997. 
[3] Hewitt, G. F., Heat exchanger design handbook 2002, York, Begell House, 2002.

[4] Zukauskas A., Convectional Heat Transfer in Heat Exchangers, Nauka: Moscow, p. 472, 1982.

[5] Gylys J., Miliauskas G., Sinkunas S., Zdankus T., Influence of vertical foam flow liquid drainage on tube bundle heat transfer intensity, The Fourth International Conference on Heat Transfer, Fluid Mechanics and Thermodynamics, Cairo, Egypt, p. [1-6], 2005.

[6] Gylys J., Sinkunas S. and Zdankus T., Experimental Study of Staggered Tube Bundle Heat Transfer in Foam Flow, 5th International Symposium on Multiphase Flow, Heat Mass Transfer and Energy Conversion, Xi'an, China, p.[1-6], 2005.

[7] Gylys J., Giedraitis V., Sinkunas S., Zdankus T., Gylys M., Study of Tube Bank Cooling in Vertical Foam Flow, IIR-IRHACE Conference, New Zealand, pp. 550-557, 2006.

[8] Gylys J., Giedraitis V., Sinkunas S., Zdankus T. and Gylys M., Study of inline tube bundle heat transfer in upward vertical foam flow, Energy: production, distribution and conservation ASME conference, Milan, Italy, pp. 643-650, 2006.

[9] Gimbutis G., Kajutis K., Krukonis V., Pranckunas A., Svencianas P., Thermal Technology, Mokslas: Vilnius, p. 333, 1993. 